CLINICAL STUDY

\title{
Clinical and biochemical description of a novel CYP21A2 gene mutation 962_963insA using a new 3D model for the P450c21 protein
}

\author{
Marco Janner, Amit V Pandey ${ }^{1}$, Primus E Mullis and Christa E Flück \\ Pediatric Endocrinology and Diabetology, University Children's Hospital Bern, Bern, Switzerland and ${ }^{1}$ Theodor Kocher Institute, University of Bern, Bern, \\ Switzerland
}

(Correspondence should be addressed to C E Flück; Email: christa.flueck@insel.ch)

Marco Janner and Amit V Pandey contributed equally to this work

\begin{abstract}
Objective: A severely virilized 46, XX newborn girl was referred to our center for evaluation and treatment of congenital adrenal hyperplasia $(\mathrm{CAH})$ because of highly elevated $17 \alpha$-hydroxyprogesterone levels at newborn screening; biochemical tests confirmed the diagnosis of salt-wasting CAH. Genetic analysis revealed that the girl was compound heterozygote for a previously reported Q318X mutation in exon 8 and a novel insertion of an adenine between nucleotides 962 and 963 in exon 4 of the CYP21A2 gene. This 962_963insA mutation created a frameshift leading to a stop codon at amino acid 161 of the $\mathrm{P} 450 \mathrm{c} 21$ protein.

Aim and methods: To better understand structure-function relationships of mutant $\mathrm{P} 450 \mathrm{c} 21$ proteins, we performed multiple sequence alignments of $\mathrm{P} 450 \mathrm{c} 21$ with three mammalian P450s (P450 2C8, 2C9 and 2B4) with known structures as well as with human P450c17. Comparative molecular modeling of human P450c21 was then performed by MODELLER using the X-ray crystal structure of rabbit $\mathrm{P} 4502 \mathrm{~B} 4$ as a template.

Results: The new three dimensional model of human P450c21 and the sequence alignment were found to be helpful in predicting the role of various amino acids in P450c21, especially those involved in heme binding and interaction with P450 oxidoreductase, the obligate electron donor.

Conclusion: Our model will help in analyzing the genotype-phenotype relationship of P450c21 mutations which have not been tested for their functional activity in an in vitro assay.

European Journal of Endocrinology 155 143-151
\end{abstract}

\section{Introduction}

Congenital adrenal hyperplasia $(\mathrm{CAH})$ consists of a group of autosomal recessive disorders of adrenal steroid hormone biosynthesis due to enzyme defects. CAH may lead to a lack of glucocorticoids, a decrease or increase of mineralocorticoids and adrenal C19 steroids (also known as adrenal androgens). In Western Europe, $90-95 \%$ of $\mathrm{CAH}$ is caused by mutations of the CYP $21 A 2$ gene. CYP21A2 encodes the steroidogenic enzyme $21 \alpha-$ hydroxylase (210Hase), which catalyzes the conversion of progesterone to 11-deoxycorticosterone in the zona glomerulosa of the human adrenal cortex, and the conversion of $17 \alpha$-hydroxyprogesterone (17OHP) to 11 deoxycortisol in the zona fasciculata (1). Genotypephenotype correlation studies of CYP21A2 mutations have shown that there are essentially three groups of 210Hase deficiency: (a) mutations causing a complete loss of 210Hase activity resulting in the classical form of salt-wasting (SW) CAH, which is clinically manifest as a severe disturbance in water and salt homeostasis due to the mineralocorticoid deficiency, and for which the affected girls often show virilization of their external genitalia at birth ranging from Prader stages 2-5 (2); (b) mutations encoding enzymes which have $1-2 \%$ of normal activity permitting normal mineralocorticoid synthesis, thus resulting in the simple virilizing (SV) form of $\mathrm{CAH}$; and (c) mutations encoding enzymes with $20-60 \%$ activity resulting in the non-classical (NC), late-onset form of $\mathrm{CAH}$ manifesting in later life.

We studied a completely virilized 46, XX baby girl who presented with the SW form of CAH. She was found to be compound heterozygote for the previously described Q318X mutation in exon 8 of the CYP21A2 gene (3), and a new mutation in exon 4. Furthermore, we built a new three dimensional (3D) model of the human P450c21 protein, which allows us to predict the structure-function relationship of different mutations in the P450c21 protein.

\section{Methods}

\section{Case report}

The patient was born at term by spontaneous, vaginal delivery after a normal pregnancy. Birth weight was $3.385 \mathrm{~g}(+0.6$ s.D. score (SDS)) and birth length was 
$50 \mathrm{~cm}(+0.5$ SDS $)$. Initially, the baby was assigned to the male sex. The parents were not consanguineous and the family history was unremarkable. A 3-year-old sister was healthy. Newborn screening of our patient at day 3 of life revealed a highly elevated serum $170 \mathrm{HP}$ (468 nmol/l; normal <30), thus the child was referred to our center for evaluation of CAH. On admittance, the weight was $3.060 \mathrm{~g}$ and the skin was icteric and dry. Detailed examination of the external genitalia revealed a hypoplastic scrotum, no palpable gonads and a penis without ventral swelling body consistent with the possibility of severely virilized female external genitalia. Accordingly, we found a normal 46, XX karyotype, and pelvic ultrasound revealed a normal uterus and enlarged adrenals. Biochemical tests revealed serum sodium of $137 \mathrm{mmol} / \mathrm{l}$ (132-142) (normal values in parentheses), potassium of $6.0 \mathrm{mmol} / \mathrm{l}$ (3.6-6.1), and chloride of $105 \mathrm{mmol} / \mathrm{l}$ (95-116). Serum glucose was $5.4 \mathrm{mmol} / \mathrm{l}(3.1-4.9)$ and total bilirubin was $230 \mu \mathrm{mol} / \mathrm{l}(2-14)$. Serum $17 \mathrm{OHP}$ was $778 \mathrm{nmol} / \mathrm{l}$ $(<30)$, adrenocorticotropin $171 \mathrm{ng} / \mathrm{l}$ (9-50), cortisol $134 \mathrm{nmol} / \mathrm{l}$ (140-470), androstenedione $279 \mathrm{nmol} / \mathrm{l}$ (0.62-1.82), dehydroepiandrosterone-sulfate $12 \mu \mathrm{mol} / \mathrm{l}$ (0.23-1.5), aldosterone $2171 \mathrm{pmol} / \mathrm{l}(<5000)$, and plasma renin activity was $379.3 \mathrm{ng} / \mathrm{l}(20-120)$. Because all these clinical and biochemical findings were consistent with the diagnosis of SW CAH, the child was started on replacement therapy with hydrocortisone and fludrocortisone. In addition, the child was reassigned to a female sex form of rearing. She is now 2 $4 / 12$ years of age and developing normally.

\section{CYP21A2 mutation analysis}

Genomic DNA was extracted from peripheral blood leucocytes after obtaining informed consent from both parents. Three fragments of the CYP21A2 gene were amplified by PCR using highly selective primers differentiating the CYP21A2 gene from the CYP21A1P pseudogene by the 8 bp deletion located in exon 3 of CYP21A1P as well as specific primers for sequencing (4). In addition, a fragment of CYP21A2 was PCR amplified independently of the $8 \mathrm{bp}$ deletion in exon 3 with the primers CYP-5 (5'-AGCTATAAGTGGCACCTCAGG-3') and CYP-14 (5'-GCATCTCCACGATGTGA-3'), with CYP-14 located in exon 6 being highly specific for CYP21A2. All PCR fragments, including the 10 exons, the exon/intron boundaries, intron 2 , intron 7 , and $380 \mathrm{bp}$ of the promoter region of the CYP21A2 gene were subjected to direct sequencing. Sequencing reactions were performed with the Thermo Sequenase Cycle sequencing kit from Amersham with IRD700 and IRD800 labeled oligonucleotides (MWGBiotech, Ebersberg, Germany) on a Licor 4200L-2 automatic DNA sequencer (Licor, Lincoln, NE, USA). Large deletions of the CYP21 gene locus on chromosome 6 and deletions leading to a loss of the 8 -nucleotide sequence in exon 3 of the CYP21A2 gene were screened and quantified by polyacrylamide electrophoresis of IRD41 labeled unspecific PCR products of exon 3 as previously reported (5). For numbering of nucleotides and amino acids the reference sequence of White et al. was used (6).

\section{Sequence alignment and molecular modeling of human P450c21}

We performed a Phi-BLAST search of the protein structures in the protein data bank (PDB) database using the $\mathrm{P} 450 \mathrm{c} 21$ amino acid sequence as a template. This method was chosen to provide preferential search parameters that allow structure-based alignment of proteins and consideration for both amino acid identity and similarity. Recently, solved structures of the rabbit P450 2B4 protein $(7,8)$ appeared near the top of our list and the inhibitor-bound structure of P450 2B4 was used as a template for building a new model of human P450c21.

An analysis of structurally conserved regions of $\mathrm{P} 450$ proteins was performed by multiple sequence alignment with two other human $\mathrm{P} 450$ structures from the PDB database, P450 2C8 and 2C9 (PDB id 1PQ2 and 10G5) that show significant sequence and structural homology with P450c21. We also included the closely related human P450c17 enzyme, which has been studied for structure-function association of natural as well as synthetic mutations by site-directed mutagenesis experiments (9). The sequences of P450c21, P450c17, P450 2B4, P450 2C8 and P450 2C9 were aligned with ClustalW (10), displayed and edited using GeneDoc (http://www.psc.edu/biomed/genedoc). Molecular modeling of human P450c21 was performed by MODELLER $(11,12)$, which uses satisfaction of spatial restraints for comparative modeling of proteins. The model was based on the X-ray crystal structure of rabbit P450 2B4 in complex with 4-(4-chlorophenyl) imidazole (PDB id 1SUO) (8), which shares $27 \%$ sequence identity and $50 \%$ similarity with the human P450c21. Several preliminary models were built and the one with the most favorable energy restraints was chosen. Model was checked with the program WHAT IF (13) for detailed validation and reports of structural parameters and compared with the Whatcheck (14) report for the crystal structure of P450 2B4. A Ramachandran plot of the model was compared with the template structure for abnormalities (14-16). A model of human P450 oxidoreductase (POR) was also constructed to study the interaction of P450c21 with POR, its obligate electron donor (17). The human POR model was based on the X-ray crystal structure of rat POR (18) which shares 94\% sequence identity with human POR. Energy minimizations of the model structures were carried out by GROMOS, models were examined and edited using DeepView (19) and images were generated using the ray tracing program POVRAY (www.povray.org). Final model 
of P450c21 was compared with the template structure and root-mean-square distance (RMSD) values were calculated by DALI $(20,21)$.

\section{Results}

\section{Identification of a new 962_963insA mutation in the CYP21A2 gene}

Clinical and biochemical findings in our patient were consistent with the diagnosis of SW CAH. Therefore, genetic analysis of the CYP21A2 gene was performed. We found on one allele, a new insertion of an adenine between nucleotides 962 and 963 in exon 4 of the CYP21A2 gene (962_963insA) (Fig. 1). This insertion of an adenine created a frameshift, which led to a stop codon at amino acid 161 truncating the P450c21 protein. To our knowledge, this mutation has not previously been identified in a patient with 210 Hase deficiency.

On the other allele, codon 318 was changed from CAG, encoding glutamine (Q), to TAG (X), a stop codon (Fig. 1). This nonsense mutation Q318X in exon 8 of the CYP21A2 gene was first reported in homozygote form in a patient presenting with severe SW CAH (3). Activity of the Q318X protein has been reported to be completely lost (3). As Q318X is present in the CYP21A1 pseudogene, this mutation in the CYP21A2 gene is thought to be formed through gene conversion during meiosis $(22,23)$. Thus, $\mathrm{Q} 318 \mathrm{X}$ is a common mutation identified in patients with 210 Hase deficiency from all over the world (24).

The novel 962_963insA mutation in our patient was inherited from the mother, while the Q318X mutation was inherited from the father; but both parents were heterozygous for their respective CYP21A2 mutation and, therefore, clinically healthy.

\section{The new P450c21 protein model}

We performed a structural alignment of the amino acid sequence of $\mathrm{P} 450 \mathrm{c} 21$ with three mammalian $\mathrm{P} 450$ proteins, which share considerable sequence homology and are available in the PDB database. We also included human P450c17 in our alignment as it is a closely related steroidogenic enzyme for which some structurefunction information is available (9). All major structural elements of $\mathrm{P} 450$ proteins aligned perfectly in all five proteins (Fig. 2). The model of P450c21 protein had a similar fold as other $\mathrm{P} 450$ structures and closely resembled the P450 2B4 structure as inferred by an RMSD value of $0.93 \AA$ obtained by the program DALI $(20,21)$. A comparison of Ramachandran plots of both
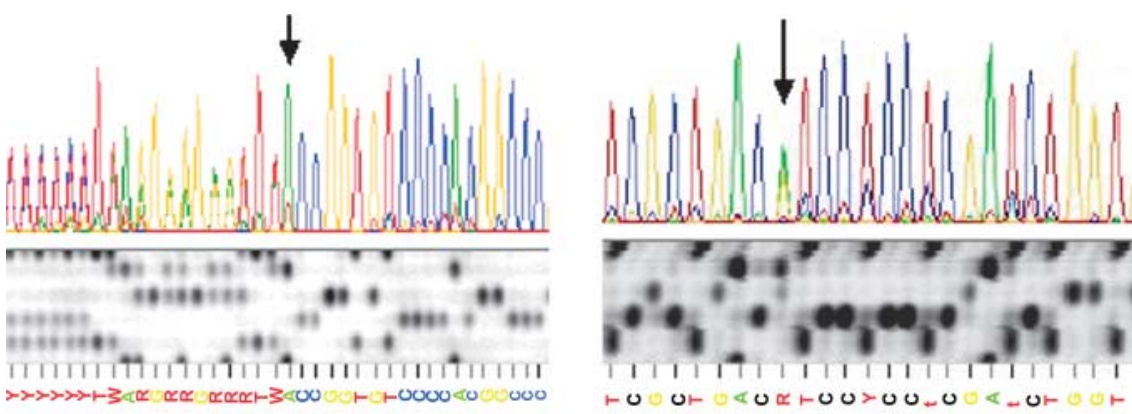

962 963ins A

Gin318X
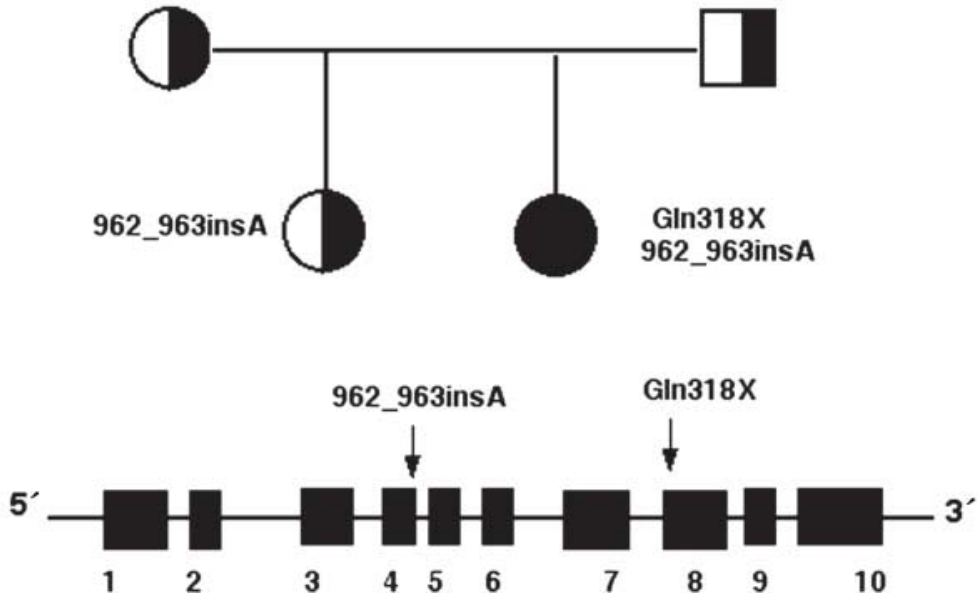

Figure 1 CYP21A2 mutation analysis. (Top) Sequence analysis showing the novel 962_963insA mutation and the previously described $\mathrm{Q} 318 X$ mutation. (Middle) Pedigree of the $\mathrm{CAH}$ index patient (black circle). (Bottom) Gene diagram. 

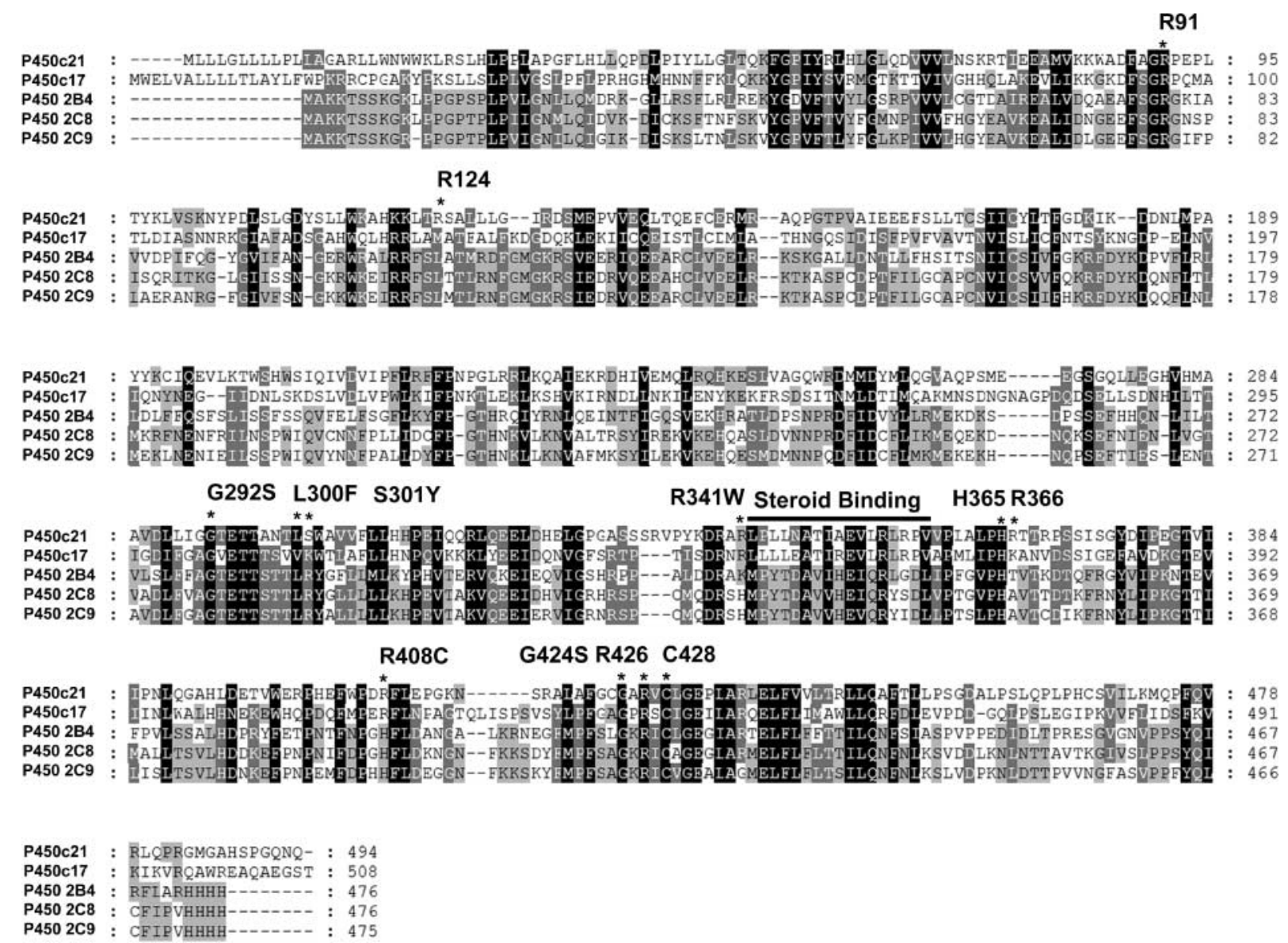

Figure 2 Multiple sequence alignment of P450c21 amino acid sequence with P450c17, P450 2B4, P450 2C8 and P450 2C9. Sequences of $\mathrm{P} 450$ 2B4, 2C8 and 2C9 used in alignment were taken from the crystal structures of these proteins in the RSCB protein structure database (http://www.rcsb.org/pdb/) and include N-terminal modifications engineered to facilitate expression in bacteria and solubilization for purification and crystallization of these proteins. The PDB identification numbers for the structures are given in parentheses. Sequence alignment was performed with CLUSTAL W (10) and edited with GENEDOC. Amino acid residues involved in heme binding (Cys424), stabilization (Arg91, Arg124, His365 and Arg426) and mutations for which experimental evidence was not available are indicated with*. All numbering is according to P450c21 amino acid sequence. The dark-shaded regions represent the amino acids conserved across all five P450s in alignment and lighter shades represent lesser levels of similarity. Despite major differences in amino acid sequence among various P450 family members, the necessary structural features needed for heme and redox partner binding are well conserved.

structures showed that our model for P450c21 had good overall structural parameters and compared well with the crystal structure of $\mathrm{P} 4502 \mathrm{~B} 4$ that was used as the template for our model (Table 1). All cytochrome $\mathrm{P} 450$ proteins have a heme ligand in the center attached covalently with a cysteine. This cysteine group is well conserved in all P450 proteins (Fig 2); Cys 428 acts as heme linker in P450c21, whereas Cys 436 has this role in $\mathrm{P} 4502 \mathrm{~B} 4(7,8)$. The heme group is stabilized by at least four amino acids forming coordinate linkages with the propionate side chains of the heme. Some of these amino acids (mostly arginines) are conserved among the members of a particular P450 family but, in general, arginine, histidine and tryptophan residues are involved in the stabilization of heme propionates groups in all $\mathrm{P} 450$ proteins. Some of these conserved arginines are also involved in the interaction with POR and form a chain for electron transfer from POR to the heme ligand. In P450 2B4 these residues are Arg 98, Arg 125, His 369, Ser 430 and Arg 434. An arginine residue (Arg 133/Arg 125 in P450 2B4) characteristic of family 2 of P450 s is found on the N-terminal helix that is involved in interaction with POR as well as stabilization of heme propionate. This arginine is well conserved in 2B4, 2C8 and 2C9 and Arg 133 is found to have this role in $\mathrm{P} 450$ 2B4 open configuration, while Arg 125/Trp 121 stabilizes one of the heme propionates in the closed structure of $\mathrm{P} 450$ 2B4 (8); in P450c21 this arginine group is absent, although another arginine at position 124 in $\mathrm{P} 450 \mathrm{c} 21$ lies $<3 \AA$ to the heme propionate and might have the same role as Arg 125/133 of 2B4. Other heme propionate ligands in $\mathrm{P} 450 \mathrm{c} 21$ are Arg 91, His 365 and Arg 426 (Arg 98, His 369 and Arg 434 in 2B4) 
Table 1 Validation parameters for the 3D model of $P 450 c 21$ compared with the crystal structure of the template (P4502B4). Model structures were evaluated with the program $\operatorname{WHATIF}(13,16)$, crystal structure of P450 2B4 was evaluated by the WhatCheck report (14) and RMSD calculations were performed with DALI $(20,21)$.

\begin{tabular}{|c|c|c|}
\hline & P450c21 model & P450 2B4 (1SUO) \\
\hline DALI RMSD value & $0.93 \AA$ & - \\
\hline $\begin{array}{l}\text { Ramachandran } \\
\text { Z score }\end{array}$ & 0.424 & 0.440 \\
\hline $\begin{array}{l}\text { RMS } Z \text { score for } \\
\text { bond angles }\end{array}$ & 0.983 & 0.836 \\
\hline $\begin{array}{l}\text { RMS } Z \text { score for } \\
\text { bond length }\end{array}$ & 0.777 & 0.689 \\
\hline $\begin{array}{l}\text { Improper dihedral } \\
\text { RMS Z score }\end{array}$ & 0.757 & 0.424 \\
\hline
\end{tabular}

that are conserved across $\mathrm{P} 450 \mathrm{~s}$ and other potential coordination linkages are likely to be Thr 295 and Leu 288.

Catalysis by $\mathrm{P} 450$ proteins is carried out through the central heme group, where oxygen binding takes place and P450 substrates are positioned to interact with heme iron for the hydroxylation reaction. A number of structural features of $\mathrm{P} 450$ proteins are needed to carry out a series of steps involving interaction of substrate to P450 and transfer of electrons from POR to P450 through positively charged groups (mostly arginines) on P450 (25), some of which are linked to heme (26). Mutant $161 \mathrm{X}$ results in a truncated $\mathrm{P} 450 \mathrm{c} 21$ protein that does not have any of its structural features required for activity and will neither bind nor metabolize substrates (Fig. 3A). It lacks structural features for holding substrates and is unable to accept electrons from POR. Mutation of Q318X also results in a truncated protein which--although larger than $161 \mathrm{X}$ protein--lacks heme and substrate binding regions required for $\mathrm{P} 450 \mathrm{c} 21$ activity (Fig 3B). This protein cannot form a complete P450 structure and will be inactive.

We analyzed some P450c21 mutants that have been identified in patients but have not been tested for their enzymatic activity in an in vitro system (Fig. 3D). Mutants G292S, L300F, R408C and G424S are reported in patients with classical forms of SW or SV CAH similar to other mutations with an identical phenotype which were tested to have $<10 \%$ of normal activity (2,27-29). Two more mutations with unknown in vitro activity are $\mathrm{S} 301 \mathrm{Y}$ and $\mathrm{R} 341 \mathrm{~W}$ for which clinical manifestation as $\mathrm{NC}$, late-onset $\mathrm{CAH}$ suggests reduced enzymatic activity $(28,30)$. All these mutations are in positions that are well conserved among all P450 structures that we analyzed (Fig. 2). Mutations G292S, $\mathrm{L} 300 \mathrm{~F}$ and S301Y are in the region of $\mathrm{P} 450 \mathrm{c} 21$ that interacts with POR and is important for electron transport. A change in topology that affects POR interaction might affect enzymatic activity in case of G292S and L300F mutations. The serine at position
301 is unique in P450c21 and a change to tyrosine might result in a different charge pattern adversely affecting the electron transfer system, although such an effect is likely to be a milder one. The mutation R341W will result in altered interaction with POR and a defective electron transfer. This arginine is conserved among all $\mathrm{P} 450$ proteins and in $\mathrm{P} 450 \mathrm{c} 17$; an $\mathrm{R} 347 \mathrm{H}$ (corresponding to R341 in P450c21) mutation has been reported to affect only 17,20 lyase activity of P450c17 (31). From the analysis of the P450c21 model, it appears that the $\mathrm{R} 341 \mathrm{~W}$ mutation may have reduced activity. The mutant R408C is likely to interfere with proper folding of the protein by the formation of an intra-molecular disulfide bond with $\mathrm{C} 428$ that is required for heme binding or, alternatively ligating to a heme molecule itself that would create a sterically unfavorable environment for heme binding to C428 and would result in a partially inactive protein. Mutation G424 is very close to the heme binding pocket $(<4 \AA)$ and a change to serine is likely to interfere with coordination linkage of the heme propionate group to R426.

\section{Discussion}

Over 80 different mutations of the CYP21A2 gene causing $\mathrm{CAH}$ have been described. Most mutations result from false recombinations between the normally active CYP21A2 gene and the inactive CYP21A1 pseudogene (24). False recombinations consist of either unequal crossing over during meiosis, which result in net deletions of CYP21A2, or apparent gene conversions transferring deleterious mutations that are normally present in the CYP21A1 pseudogene to CYP21A2.

The patient with $\mathrm{CAH}$ described here suffered from severe deficiency of mineralocorticoids and glucocorticoids due to the absence of 210 Hase activity. She was found to be compound heterozygous for the mutations Q318X and 962_963insA of the CYP21A2 gene. Q318X is a common mutation of the CYP21A2 gene formed by gene conversion between the CYP21A1 pseudogene and the active CYP21A2 gene causing a complete loss of 210 Hase activity (3). Thus, Q318X is frequently found in patients with SW CAH (1).

In contrast, the 962_963insA mutation has not been described previously. Rarely, insertions cause 210 Hase deficiency (Table 2) (28,32-35). Reviewing the literature, we found a total of four different insertions of a single nucleotide among all known CYP21A2 mutations. The insertion of a thymine at position F306 in exon 7 seems to be the most common insertion (Table 2). This mutation may be found alone or in a cluster with other mutations but was never found in homozygous form $(28,32,33)$. Clustering of the pseudogene-derived mutations in exons 7 and 8 (V281LF306insT-Q318X-R356W) seems to be more frequent in the Dutch population (28). The 995_996insA 

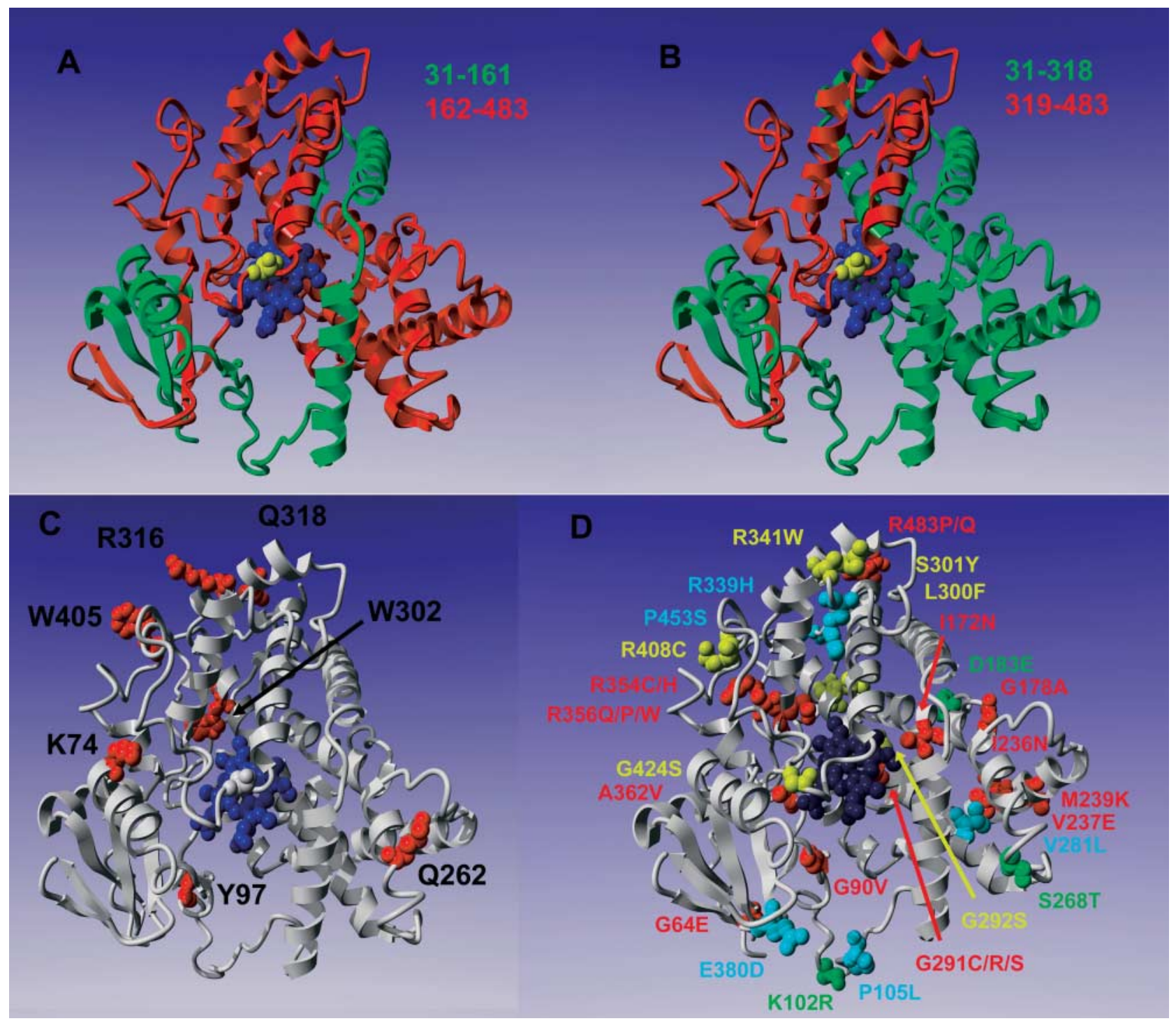

Figure 3 Molecular modeling of the human P450c21 protein. The 3D model of human P450c21 protein was constructed using the program MODELLER and was based on the crystal structure of mammalian P450 2B4 that shares $50 \%$ sequence similarity with P450c21 amino acid sequence. We used an inhibitor bound form of the P450 2B4 structure (1SUO) as a template for our model of P450c21. (A) Model of $\mathrm{P} 450 \mathrm{c} 21$, amino acids 31-161 are depicted in green and the missing part of the P450c21 structure in 161X truncated protein is shown in red. The central heme ligand is in dark blue and cysteine 428 that links to heme iron is shown in yellow as CPK spheres. (B) Model of P450c21 with amino acids $31-318$ in green and the missing part of the structure in $318 \mathrm{X}$ mutant depicted in red. The cysteine 428 that binds to the central iron of the heme the group is found on the missing part of the structure in the truncated protein. (C) Known nonsense mutations of P450c21 depicted in the protein model. These mutations create premature stop codons in the P450c21 sequence and result in a P450 protein without a heme binding site (Cys 428) and many of them also lack other structural features due to truncations as early as aa 74 . None of these proteins can either bind nor metabolize its substrates. The P450c21 protein is depicted as a ribbon model. The central heme group is shown in blue, cysteine 428 in grey and nonsense mutations are shown as red CPK spheres. (D) Reported missense mutations of P450c21. A ribbons diagram model of P450c21 protein is shown with the central heme group (blue) and cysteine 428 (yellow) as CPK spheres. Mutations with $<10 \%$ of normal activity are shown in red, $10-60 \%$ activity in blue and $100 \%$ activity in green; mutations with unknown in vitro activity are shown in yellow.

mutation in exon 4 was found in the compound heterozygous form in one female patient with SV CAH (28). The H28insC mutation in exon 1 was found homozygote in one Brazilian girl whose parents were consanguineous (35). This $\mathrm{H} 28$ insC mutation leads to a stop codon at amino acid 78 and thus to a complete loss of 210 Hase activity. Similarly, the 64insT mutation in exon 1 was described in the homozygous form in a boy of non-consanguineous parents from a rural area in Spain and leads to a frameshift generating a stop codon in exon 2. In addition to these four single nucleotide insertions, insertion of $16 \mathrm{nt}$ after codon V397 has been 
Table 2 Genotype and phenotype correlations in patients with CYP21A2 mutations including the insertion of a nucleotide.

\begin{tabular}{|c|c|c|c|c|c|c|c|c|c|}
\hline \multirow[b]{3}{*}{ Reference } & \multirow[b]{3}{*}{ Allele 1} & \multirow[b]{3}{*}{ Allele 2} & \multicolumn{6}{|c|}{ Phenotype } & \multirow[b]{3}{*}{ Prader stage } \\
\hline & & & \multicolumn{3}{|c|}{$\mathrm{XY}$, males } & \multicolumn{3}{|c|}{$X X$, females } & \\
\hline & & & SW & SV & $\mathrm{NC}$ & SW & SV & $\mathrm{NC}$ & \\
\hline 34 & 64insT & 64insT & 1 & & & & & & \\
\hline 32 & $\begin{array}{l}\text { I172N-CL6-F306insT- } \\
\text { Q318X }\end{array}$ & CL6 & & & & 1 & & & 4 \\
\hline 32 & $\begin{array}{l}\text { CL6-V281L-F306insT- } \\
\text { Q318X-R356W }\end{array}$ & Q318X-R356W & & & & 1 & & & 4 \\
\hline 32 & Del & F306insT-Q318X-R356W & & & & 1 & & & 4 \\
\hline 32 & V281L & CL6-F306insT-V281L & & 1 & & & & & \\
\hline 28 & CL6 & $\begin{array}{l}\text { V281L-F306insT-Q318X- } \\
\text { R356W }\end{array}$ & & & & 1 & & & n.s. \\
\hline 28 & $\mathrm{I} 2 \mathrm{G}$ & F306insT & 1 & & & & & & \\
\hline 28 & $\mathrm{I172N}$ & $\begin{array}{l}\text { V281L-F306insT-Q318X- } \\
\text { R356W }\end{array}$ & & & & 1 & & & n.s. \\
\hline 28 & 1123delC & $\begin{array}{l}\text { V281L-F306insT-Q318X- } \\
\text { R356W }\end{array}$ & & & & 2 & & & n.s. \\
\hline 28 & 995_996insA & $\mathrm{del} / \mathrm{con}$ & & & & & 1 & & n.s. \\
\hline 33 & $10 \mathrm{bp}$ del & F306insT & & & & 1 & & & n.s. \\
\hline 35 & $\mathrm{H} 28 \mathrm{insC}$ & $\mathrm{H} 28 \mathrm{ins} \mathrm{C}$ & & & & 1 & & & 3 \\
\hline * & Q318X & 962_963insA & & & & 1 & & & 5 \\
\hline
\end{tabular}

SW, classic salt wasting; SV, simple virilizing; NC, non-classic; CL6, cluster containing three mutations in exon 6 (I236N, V237E, and M239K); n.s., not specified. *Index patient described in this paper.

reported in a Chinese $\mathrm{CAH}$ patient (33), and two complex mutations combining insertions with deletions have been identified as C168delTGinsA (36) and R482delGGinsC (37). In general, all reported insertions created frameshifts, which resulted in truncated and thus functionally inactive $\mathrm{P} 450 \mathrm{c} 21$ proteins. This is also true for the newly identified 962_963insA mutation, which leads to a stop codon at aa 161 of the P450c21 protein.

For structure-function studies we generated a new model for the $\mathrm{P} 450 \mathrm{c} 21$ protein. Some earlier 3D models of P450c21 have been described but these were based on structures of bacterial P450s $(38,39)$. Mammalian type $2 \mathrm{P} 450$ proteins that are localized in the endoplasmic reticulum are dependent on a separate protein known as NADPH POR for the supply of electrons (40). P450 reductase is a flavoprotein that transfers electrons from NADPH to the heme ligand of cytochrome P450s via FAD and FMN moieties that are part of POR. This interaction is achieved via arginine and lysine residues on P450s and aspartic and glutamic acid residues on POR. In contrast, bacterial type 2 P450 BM3, on which the previous models were based, has an in-built flavoprotein electron transfer domain $(41,42)$. Recent advances in crystallization and structure determination of $\mathrm{P} 450$ proteins has led to the availability of seven mammalian $\mathrm{P} 450$ structures in the $\mathrm{PDB}$ database, namely $\mathrm{P} 4502 \mathrm{~A} 6,2 \mathrm{~B} 4,2 \mathrm{C} 5,2 \mathrm{D} 6,2 \mathrm{C} 8$, 2C9 and 3A4. Our model is based on rabbit $\mathrm{P} 450$ 2B4, a mammalian $\mathrm{P} 450$ protein whose structure has recently been solved $(7,8)$ and which shares better sequence homology with P450c21 than bacterial P450 proteins. Moreover, P450 2B4 has been the subject of extensive site-directed mutagenesis studies that provided information not only about active site composition but also POR-P450 interaction (26). We have analyzed our model based on P450 2B4 and human P450c17, which is a closely related enzyme and participates in the catabolism of cholesterol metabolites such as P450c21. Our new model is based on a closely related mammalian P450 that has both open and substrate bound forms of the structure available. Recent structural studies of P450 proteins have demonstrated dynamic structural rearrangements in the $\mathrm{P} 450$ structures after substrate binding that also affects the way a P450 might interact with its electron donating partners (43). Structure-function prediction based on our model and sequence alignment allows us more accurately to predict the role of various amino acids in $\mathrm{P} 450 \mathrm{c} 21$ protein that take part in heme binding and interaction with POR. This will also help in analyzing mutations that are reported to cause $\mathrm{CAH}$, since we can predict the role of individual amino acids in P450c21 for its enzymatic activity with better accuracy.

\section{Acknowledgements}

We thank Drs S Clausmeyer and E Schulze of the molecular diagnostic laboratory Dres Raue, Hentze, Heidelberg, Germany for the genetic analysis of the CYP21A2 gene. This work was supported by grants of the Swiss National 
Science Foundation: 3232B0103178/179 to CEF and 3200-064623.01 to PEM.

\section{References}

1 Speiser PW \& White PC. Congenital adrenal hyperplasia. New England Journal of Medicine 2003349 776-788.

2 Krone N, Braun A, Roscher AA, Knorr D \& Schwarz HP. Predicting phenotype in steroid 21-hydroxylase deficiency? Comprehensive genotyping in 155 unrelated, well defined patients from southern Germany. Journal of Clinical Endocrinology and Metabolism $2000 \mathbf{8 5}$ 1059-1065.

3 Globerman H, Amor M, Parker KL, New MI \& White PC. Nonsense mutation causing steroid 21-hydroxylase deficiency. Journal of Clinical Investigation 1988 82 139-144.

4 Schulze E, Scharer G, Rogatzki A, Priebe L, Lewicka S, Bettendorf M, Hoepffner W, Heinrich UE \& Schwabe U. Divergence between genotype and phenotype in relatives of patients with the intron 2 mutation of steroid-21-hydroxylase. Endocrine Research 199521 359-364.

5 Beuschlein F, Schulze E, Mora P, Gensheimer HP, Maser-Gluth C, Allolio B \& Reincke M. Steroid 21-hydroxylase mutations and 21-hydroxylase messenger ribonucleic acid expression in human adrenocortical tumors. Journal of Clinical Endocrinology and Metabolism $1998 \mathbf{8 3} 2585-2588$.

6 White PC, New MI \& Dupont B. Structure of human steroid 21-hydroxylase genes. PNAS 198683 5111-5115.

7 Scott EE, He YA, Wester MR, White MA, Chin CC, Halpert JR, Johnson EF \& Stout CD. An open conformation of mammalian cytochrome P450 2B4 at 1.6-A resolution. PNAS $2003 \mathbf{1 0 0}$ 13196-13201.

8 Scott EE, White MA, He YA, Johnson EF, Stout CD \& Halpert JR. Structure of mammalian cytochrome P450 2B4 complexed with 4-(4-chlorophenyl)imidazole at 1.9-A resolution: insight into the range of $\mathrm{P} 450$ conformations and the coordination of redox partner binding. Journal of Biological Chemistry 2004279 27294-27301.

9 Auchus RJ \& Miller WL. Molecular modeling of human P450c17 (17 $\alpha$-hydroxylase/17,20-lyase): insights into reaction mechanisms and effects of mutations. Journal of Molecular Endocrinology $1999131169-1182$.

10 Thompson JD, Higgins DG \& Gibson TJ. CLUSTAL W: improving the sensitivity of progressive multiple sequence alignment through sequence weighting, position-specific gap penalties and weight matrix choice. Nucleic Acids Research (Online) $1994224673-4680$.

11 Sali A \& Blundell TL. Comparative protein modelling by satisfaction of spatial restraints. Journal of Molecular Biology $1993234779-815$.

12 Fiser A, Do RK \& Sali A. Modeling of loops in protein structures. Protein Science: A Publication of the Protein Society 20009 1753-1773.

13 Vriend G. WHAT IF: a molecular modeling and drug design program. Journal of Molecular Graphics and Modelling 1990852 56.

14 Hooft RW, Vriend G, Sander C \& Abola EE. Errors in protein structures. Nature $1996 \mathbf{3 8 1} 272$.

15 Ramachandran GN, Ramakrishnan C \& Sasisekharan V. Stereochemistry of polypeptide chain configurations. Journal of Molecular Biology 19637 95-99.

16 Hooft RW, Sander C \& Vriend G. Objectively judging the quality of a protein structure from a Ramachandran plot. Computer Applied Biosciences 199713 425-430.

17 Huang N, Pandey AV, Agrawal V, Reardon W, Lapunzina PD, Mowat D, Jabs EW, Van Vliet G, Sack J, Fluck CE \& Miller WL. Diversity and function of mutations in P450 oxidoreductase in patients with Antley-Bixler syndrome and disordered steroidogenesis. American Journal of Human Genetics 200576 729-749.
18 Wang M, Roberts DL, Paschke R, Shea TM, Masters BSS \& Kim JJ. Three-dimensional structure of NADPH-cytochrome P450 reductase: prototype for FMN- and FAD-containing enzymes. PNAS $1997948411-8416$.

19 Guex N \& Peitsch MC. SWISS-MODEL and the Swiss-Pdb Viewer: an environment for comparative protein modeling. Electrophoresis $1997182714-2723$.

20 Dietmann S, Park J, Notredame C, Heger A, Lappe M \& Holm L. A fully automatic evolutionary classification of protein folds: Dali Domain Dictionary version 3. Nucleic Acids Research 200129 55-57.

21 Holm L \& Park J. DaliLite workbench for protein structure comparison. Bioinformatics 200016 566-567.

22 Donohoue PA, van Dop C, McLean RH, White PC, Jospe N \& Migeon CJ. Gene conversion in salt-losing congenital adrenal hyperplasia with absent complement $\mathrm{C} 4 \mathrm{~B}$ protein. Journal of Clinical Endocrinology and Metabolism 1986 62 995-1002.

23 Tusie-Luna MT \& White PC. Gene conversions and unequal crossovers between CYP21 (steroid 21-hydroxylase gene) and CYP21P involve different mechanisms. PNAS $1995 \mathbf{9 2}$ 10796-10800.

24 White PC \& Speiser PW. Congenital adrenal hyperplasia due to 21-hydroxylase deficiency. Endocrine Reviews 200021 245-291.

25 Shen AL \& Kasper CB. Role of acidic residues in the interaction of NADPH-cytochrome P450 oxidoreductase with cytochrome P450 and cytochrome c. Journal of Biological Chemistry $1995 \mathbf{2 7 0}$ 27475-27480.

26 Bridges A, Gruenke L, Chang YT, Vakser IA, Loew G \& Waskell L. Identification of the binding site on cytochrome P450 2B4 for cytochrome b5 and cytochrome $\mathrm{P} 450$ reductase. Journal of Biological Chemistry 1998273 17036-17049.

27 Miller WL. Clinical review 54: Genetics, diagnosis, and management of 21-hydroxylase deficiency. Journal of Clinical Endocrinology and Metabolism 199478 241-246.

28 Stikkelbroeck NM, Hoefsloot LH, de Wijs IJ, Otten BJ, Hermus AR \& Sistermans EA. CYP21 gene mutation analysis in 198 patients with 21-hydroxylase deficiency in The Netherlands: six novel mutations and a specific cluster of four mutations. Journal of Clinical Endocrinology and Metabolism 200388 3852-3859.

29 Billerbeck AE, Bachega TA, Frazatto ET, Nishi MY, Goldberg AC, Marin ML, Madureira G, Monte O, Arnhold IJ \& Mendonca BB. A novel missense mutation, GLY424SER, in Brazilian patients with 21-hydroxylase deficiency. Journal of Clinical Endocrinology and Metabolism $1999842870-2872$.

30 Lajic S, Levo A, Nikoshkov A, Lundberg Y, Partanen J \& Wedell A. A cluster of missense mutations at Arg356 of human steroid 21-hydroxylase may impair redox partner interaction. Human Genetics $199799704-709$.

31 Geller DH, Auchus RJ \& Miller WL. P450c17 mutations R347H and R358Q selectively disrupt 17,20-lyase activity by disrupting interactions with P450 oxidoreductase and cytochrome b5. Molecular Endocrinology 199913 167-175.

32 Speiser PW, Dupont J, Zhu D, Serrat J, Buegeleisen M, Tusie-Luna MT, Lesser M, New MI \& White PC. Disease expression and molecular genotype in congenital adrenal hyperplasia due to 21-hydroxylase deficiency. Journal of Clinical Investigation 199290 584-595.

33 Lee HH, Chao HT, Lee YJ, Shu SG, Chao MC, Kuo JM \& Chung BC. Identification of four novel mutations in the CYP21 gene in congenital adrenal hyperplasia in the Chinese. Human Genetics $1998103304-310$.

34 Ezquieta B, Oyarzabal M, Jariego CM, Varela JM \& Chueca M. A novel frameshift mutation in the first exon of the $21-\mathrm{OH}$ gene found in homozygosity in an apparently nonconsanguineous family. Hormone Research 199951 135-141.

35 Lau IF, Soardi FC, Lemos-Marini SH, Guerra G Jr, Baptista MT \& De Mello MP. H28 + C insertion in the CYP21 gene: a novel frameshift mutation in a Brazilian patient with the classical form of 21hydroxylase deficiency. Journal of Clinical Endocrinology and Metabolism $2001 \mathbf{8 6} 5877-5880$. 
36 Witchel SF, Smith R \& Suda-Hartman M. Identification of CYP21 mutations, one novel, by single strand conformational polymorphism (SSCP) analysis. Mutations in brief no. 218. Online. Human Mutation 199913172.

37 Ritzen EM, Haglund-Stengler B, Dorobek W \& Luthman H. Clinical forms of congenital adrenal hyperplasia: restriction length polypmorphism patterns in the CYP21 gene. Acta Paediatrica Japonica 198830 (Suppl) 99-104.

38 Lewis DF \& Lee-Robichaud P. Molecular modelling of steroidogenic cytochromes P450 from families CYP11, CYP17, CYP19 and CYP21 based on the CYP102 crystal structure. Journal of Steroid Biochemistry and Molecular Biology 199866 217-233.

39 Mornet E \& Gibrat JF. A 3D model of human P450c21: study of the putative effects of steroid 21-hydroxylase gene mutations. Human Genetics 2000106 330-339.

40 Lu AY, Junk KW \& Coon MJ. Resolution of the cytochrome P-450containing $\omega$-hydroxylation system of liver microsomes into three components. Journal of Biological Chemistry $19692443714-3721$.
41 Warman AJ, Roitel O, Neeli R, Girvan HM, Seward HE, Murray SA, McLean KJ, Joyce MG, Toogood H, Holt RA, Leys D, Scrutton NS \& Munro AW. Flavocytochrome P450 BM3: an update on structure and mechanism of a biotechnologically important enzyme. Biochemical Society Transactions 200533 747-753.

42 Sevrioukova IF, Li H, Zhang H, Peterson JA \& Poulos TL. Structure of a cytochrome P450-redox partner electron-transfer complex. PNAS 199996 1863-1868.

43 Poulos TL. Cytochrome P450 flexibility. PNAS 2003100 13121-13122.

Received 12 January 2006

Accepted 29 March 2006 